\title{
Die Weltformel
}

Erhard Taverna

erhard.taverna@saez.ch
Wer lange am Treffpunkt wartet, kann in Ruhe die grösste und schönste Bahnhofhalle der Schweiz betrachten. Im Zentrum eines Kunstdreiecks steht er, tonnenschwer und überirdisch leicht, Niki de Saint Phalles Engel, schwebend über der Menschenmenge. Der Engel teilt den Bahnhofshimmel mit zwei Lichtspielen, die mit beginnender Dämmerung an Tiefe und Intensität gewinnen. Beiden Objekten, dem NovaWürfel mit seinen aufschimmernden Farbwolken und der immer heller leuchtenden Neonspirale auf dem verglasten Oberlicht der Westfassade, liegen Algorithmen zugrunde, die unsere Welt erklären sollen. Die Lichtwolke ist ein Geschenk der ETH, eine ausgeklügelte Maschinerie als Sinnbild der Wissenschaft, gleichsam ein ideeller Zwilling der 1992 von Mario Merz (1925-2003) gestalteten Spirallichtskulptur. Das Werk des Turiner Künstlers mit dem Titel «Das philosophische Ei», gestiftet vom Zürcher Kunstverein, wollte gleichermassen Natur und Wissenschaft zusammenfügen. Bei genauerer Betrachtung werden die dunklen Umrisse von Tieren sichtbar und dazwischen verteilt eine lange Folge von Zahlen, denen jede die Summe der beiden vorausgehenden abbildet. Mario Merz wurde als Vertreter der «Arte Povera» vor allem durch seine Iglus bekannt. Er hat sich nach einem abgebrochenen Medizinstudium ganz der Malerei zugewandt und neue Ausdrucksformen für eine eigenständige Utopie gefunden. Bei Leonardo da Pisa entdeckte er die berühmten Fibonacci-Zahlenreihen, die er in vielen Darstellungen als Metaphern für Wachstum und Fortpflanzung variiert. Seine mit zahlreichen Preisen ausgezeichneten Installationen (Objekte und Gemälde) sind heute Teil der internationalen Kunstszene.

Wer lange genug am Treffpunkt ausharrt, hat Musse, über diese scheinbar einfachen Zahlen nachzudenken. Irgendeine Kaninchenrechnung war da am Anfang, und, dass der Mathematiker aus Pisa das indisch-arabische Dezimalsystem in Europa einführte, ist noch knapp als Schulwissen abrufbar. Wie hing das mit dem goldenen Schnitt zusammen? Zum Glück hat die Warterei ein Ende, das Suchen kann bequemer $\mathrm{zu}$ Hause weitergehen. Lange ist es her, dass ein geschätzter Mathematiklehrer und sein Geschichtskollege begeistert von der «Divina proporzione» berichteten, geometrische Aufgaben verteilten oder die ausgewogene Schönheit des griechischen Parthenon priesen. Die göttliche Proportion:

Man teile eine Strecke in zwei Teile, so dass der kleinere Teil (Minor) sich zum grösseren Teil (Major) genauso verhält, wie der grössere Teil zum Ganzen. Die lineare Abfolge dieser Strecken, also Minor, Major und das Ganze aneinandergereiht, entspricht dem Neben-

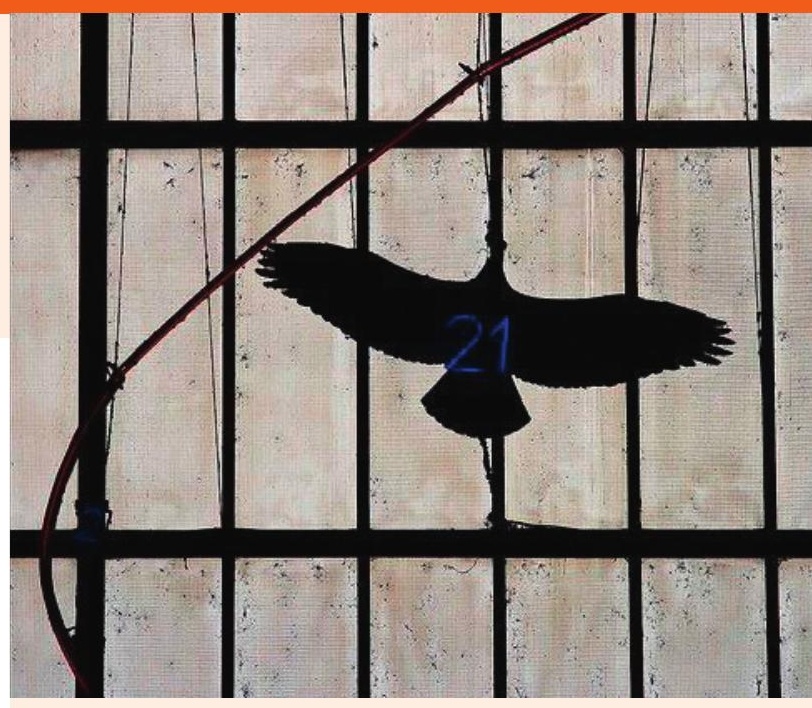

Ausschnitt aus dem Werk «Das philosophische Ei» von Mario Merz, das im Zürcher Bahnhof über den Köpfen der Reisenden schwebt.

einander der Fibonaccizahlen. Drückt man das Verhältnis der Teilstrecken in Zahlen aus, ergibt sich eine Konstante Phi $=1,61803 \ldots$, eine irrationale Zahl, in der viele eine Art Weltformel gefunden haben. Was 1202 in Pisa mit dem «Liber abaci» begann, wurde zu einem universalen Wachstumsprinzip ausgeweitet. Von den Längenmassen der Kreditkarte über Blütenstrukturen und Blattzyklen, von Aktienkursen bis zum Bau der Spiralnebel scheinen Symmetrie und Asymmetrie den geheimnisvollen Fibonacciregeln zu gehorchen.

Verantwortlich für diese erstaunliche Entwicklung war Adolf Zeising (1810-1876), ein deutscher Mediziner und Philosoph, der in den vergangenen Proportionstheorien ein universales morphologisches Grundgesetz entdeckte. Der Astronom Kepler hatte als erster Autor die mathematischen Beziehungen des goldenen Schnitts und der Fibonaccizahlen mit Elementen der Natur verbunden. Zeising ging noch weiter, vermass Menschen und Körperteile und verglich sie mit den Idealmassen griechischer Statuen. Die Übereinstimmungen sind eindrücklich und als ästhetische Regeln in der Schönheitschirurgie und Zahnmedizin bedeutsam geblieben. In den Ringen des Saturns, in vielen Mozartsonaten und in der fraktalen Geometrie, überall steckt Fibonacci. Effizienz, Transzendenz, Zahlenakrobatik, Mythos oder nur Sehnsucht nach Harmonie und Schönheit? Die Faszination ist ungebrochen. Ein Bestsellerautor wie Dan Brown hat die Zahl Phi wieder populär gemacht. Im Roman «Sakrileg» lehrt der Symbolforscher Robert Langdon seine Studenten, den Abstand von ihrem Scheitel bis zum Fussboden zu messen und durch den Abstand der Strecke Nabel-Fussboden zu teilen. Phi wird zur Lieblingszahl Gottes, zum mikro- und makrokosmischen Prinzip. Algorithmen beherrschen die Technik. Mathematik und Geometrie formen unseren sechsten Sinn, sie sind Ausdruck unserer eigenen zerebralen Ordnung. «Nimm allem die Zahl und alles zerfällt» hat schon Isidor von Sevilla festgestellt. Wer war dieser Isidor? Wie gut, dass es den Treffpunkt mit seinen Wartezeiten gibt ... 